\title{
ZINC-OXIDE THIN FILMS FOR INTEGRATED-SENSOR APPLICATIONS
}

\author{
D.L. Polla and R.S. Muller \\ Department of Electrical Engineering and Computer Sciences \\ and the Electronics Research Laboratory \\ University of California, Berkeley, California 94720
}

\begin{abstract}
Integrated sensors based on the piezoelectricity and pyroelectricity in zinc-oxide thin films have been fabricated compatibly with conventional NMOS technology. A study of material and electrical properties of the zinc-oxide films, prepared by planar magnetron sputtering, has been carried out. For $1-\mu \mathrm{m}$ thick films, the measured piezoelectric coefficient is $\mathrm{d}_{33}=14.4 \times 10^{-12} \mathrm{CN}^{-1}$ and the pyroelectric coefficient is $\mathrm{p}^{\sigma}=1.4 \times 10^{-9} \mathrm{Ccm}^{-2} \mathrm{~K}^{-1}$. In practical integrated sensor designs, these films have yielded voltage responses of $5.2 \mathrm{mV} / \mathrm{gm}$ (piezoelectric effect) and $150 \mathrm{mV} / \mathrm{K}$ (pyroelectric effect).
\end{abstract}

\section{INTRODUCTION}

Thin films of zinc oxide have been combined with conventional silicon planar processing techniques to form integrated sensors in which a physical or chemical variable is sensed and transduced to an on-chip amplifier circuit. Integrated sensors using zinc-oxide thin films that have been fabricated and demonstrated to date in our laboratory include:

(1) cantilever-beam accelerometer [1],

(2) SAW convolver [2],

(3) chemical vapor sensor [3],

(4) anemometer [4],

(5) inf rared detector array [5],

(6) chemical reaction sensor [6],

(7) tactile sensor array [7], and

(8) inf rared charge-coupled device imager [8].

The operation of all sensors was based on the piezoelectric or pyroelectric effects in the zinc-oxide films.

This paper focuses on the material properties of zinc-oxide thin films and the basic design considerations for integrated-sensor applications such as those listed above.

\section{ZINC-OXIDE THIN-FILM DEPOSITION}

Techniques which have previously been used for zinc-oxide thin-film deposition include $\mathrm{rf}$ and $\mathrm{dc}$ sputtering $[9,10]$, chemical-vapor deposition [11], ion plating [12], planar-magnetron sputtering [13], and reactive magnetron sputtering [14]. Our work has been based on films made using planar magnetron sputtering as the deposition technique. We chose this method because of its low film damage due to electron bombardment and high deposition rate.

Zinc-oxide thin-film crystallinity, obtained under varying sputtering conditions (substrate temperature, sputter power, thickness, ambient gas mixture), has been studied by $\mathrm{x}$-ray diffraction and scanning electron microscopy. Highly-oriented zincoxide films have been deposited on $\mathrm{SiO}_{2} / \mathrm{Si}$ and $\mathrm{SiO}_{2} / \mathrm{Poly}-\mathrm{Si} / \mathrm{Si}$ substrates. X-ray diffraction measurements indicate preferential $c$ - axis orientation with a single diff raction peak at $33.8^{\circ}$ in the best samples studied as shown in Fig. 1. Based on x-ray diff raction studies, we have found the best thin-film crystallinity to correspond to deposition conditions carried out at a forward sputtering power of $200 \mathrm{~W}$ with a $10 \mathrm{mTorr}$ ambient gas mixture consisting of $50 \%$ oxygen and 50\% argon. The substrate to target distance is $4 \mathrm{~cm}$ and the substrate temperature is maintained at $230^{\circ} \mathrm{C}$ during deposition.

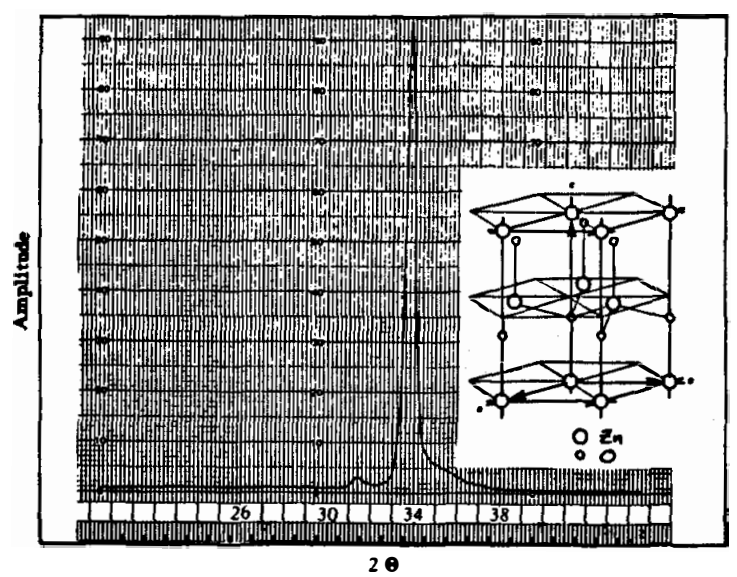

Fig. 1. Typical $\mathrm{x}$-ray diffraction spectrum characterizing the preferential $c$ - axis orientation in zinc-oxide thin films prepared by planar magnetron sputtering. 


\section{MATERIAL CHARACTERIZATION}

Pyroelectric and piezoelectric properties have been measured by electrical techniques and correlated with the $x$-ray diffraction results. The measured pyroelectric coefficient at $\mathrm{T}=300 \mathrm{~K}$ is $\mathrm{p}^{\sigma}=1.4 \times 10^{-9}$ $\mathrm{Ccm}^{-2} \mathrm{~K}^{-1}$ and piezoelectric coefficient is $\mathrm{d}_{33}=14.4 \times 10^{-12} \mathrm{CN}^{-1}$, in good agreement with the range of reported values in crystalline zinc oxide $[15,16]$. The temperature dependence of these coefficients is shown in Figs. 2 and 3. For typical sensor applications in $1 \mu \mathrm{m}$-thick films at $\mathrm{T}=300 \mathrm{~K}$, these coefficients imply signal levels of $5.2 \mathrm{mV} / \mathrm{gm}$ (piezoelectric effect) and $150 \mathrm{mV} / \mathrm{K}$ (pyroelectric effect). Thin films that exhibit good piezoelectric properties were also found to exhibit good pyroelectric properties.

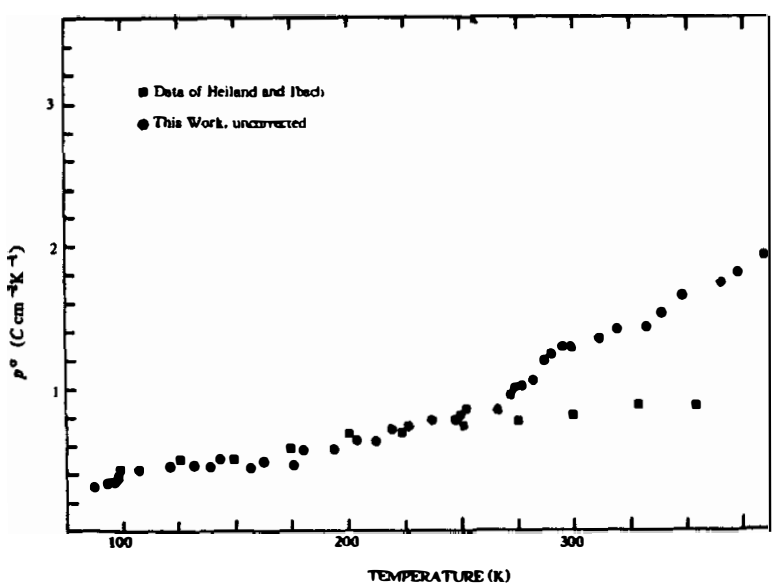

Fig. 2. Measurement of pyroelectric coefficient versus temperature in a $1.0-\mu \mathrm{m}$-thick zinc-oxide film.

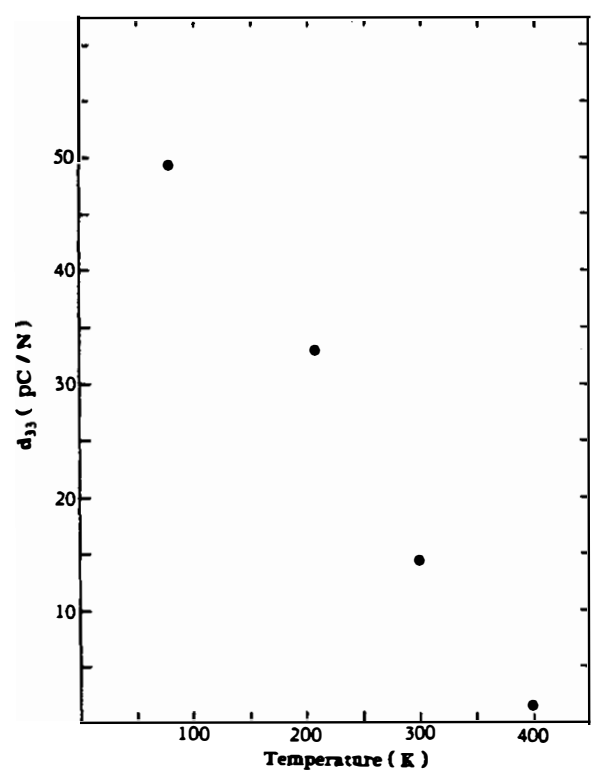

Fig. 3. Temperature dependence of the piezoelectric coefficient $d_{33}$.
The ability to fabricate sensors with a near dc response is based on the fact that typical film thicknesses $(1 \mu \mathrm{m})$ are much thinner than a Debye length $(120 \mu \mathrm{m})$. Static charge decay times (see Fig. 4) in excess of 32 days have been measured in these films when encapsulated by $0.4 \mu \mathrm{m}$-thick layers of $\mathrm{SiO}_{2}$. Thin-film resistivities of $3 \times 10^{7} \Omega-\mathrm{cm}$ and dielectric constants of $\epsilon_{\mathrm{r}}=10.3$ have been characterized in these thin-films.

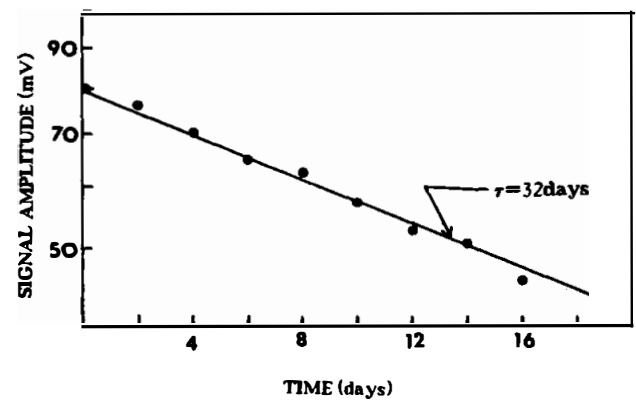

Fig. 4. Pyroelectric charge decay under conditions of constant infrared radiation. The indicated slope represents the characteristic charge retention time for zinc-oxide thin films encapsulated by silicon dioxide.

\section{CONCLUSIONS}

Zinc-oxide thin films with very useful piezoelectric and pyroelectric properties have been prepared by planar magnetron sputtering. The material and electrical properties characterized in these films have been utilized in the design and fabrication of diverse integrated sensors compatibly fabricated using NMOS technology. The performance of these sensors demonstrates: 1) the versatility of zinc-oxide thinfilm technology for integrated-sensing applications based on either the piezoelectric or pyroelectric effect, and 2) the possibility of carrying out multifunction sensing on one integrated-circuit chip.

\section{Acknowledgements}

This work was supported in part by the National Science Foundation under Grant ECS 81-20562 and in part by the State of California MICRO program.

\section{REFERENCES}

[1] P.-L. Chen, R.S. Muller, R.D. Jolly, G.L. Halac, R.M. White, A.P. Andrews, T.C. Lim, and M.E. Motamedi, "Integrated Silicon Microbeam PIFET Accelerometer," IEEE Electron Dev. ED-29, 27-32 (1983).

[2] A.E. Comer and R.S. Muller, "A New ZnO on Si Convolver Structure," IEEE Electron Dev. Lett. $E D L-3,118-120$ (1982). 
[3] C.T. Chuang and R.M. White, "Sensors utilizing thin membrane SAW oscillators," Proc. IEEE Ultrasonics Symposium, Chicago, IL, 1981.

[4] D.L. Polla, R.S. Muller, and R.M. White, "Monolithic Zinc-Oxide on Silicon Pyroelectric Anemometer," IEEE International Electron Devices Meeting, Washington, D.C. 1983.

[5] D.L. Polla, R.S. Muller, and R.M. White, "Fully-Integrated $\mathrm{ZnO}$ on Silicon Infrared Detector Array," IEEE International Electron Devices Meeting, San Francisco, CA 1984.

[6] D.L. Polla, R.M. White, and R.S. Muller, "Integrated Chemical-Reaction Sensor," Third International Conference on Solid-State Sensors and Actuators, Philadelphia, PA 1985.

[7] D.L. Polla, W.T. Chang, R.S. Muller, and R.M. White, "Integrated Zinc Oxide-on-Silicon Tactile Sensor Array," IEEE International Electron Devices Meeting, Washington, D.C. 1985.

[8] [18] D.L. Polla, R.M. White, and R.S. Muller, "Integrated Multi-Sensor Chip," IEEE Electron Dev. Lett., (to be published in 1986).

[9] H.W. Lehmann and R. Widmer, "RF Sputtering of ZnO Shear-Wave Transducers," J. Appl. Phys. 44, 3868-3879 (1973).

[10] G.A. Rozgonyi and W.J. Polito, "Preparation of $\mathrm{ZnO}$ Thin Films by Sputtering of the Compound in Oxygen and Argon," Appl. Phys. Lett. 8, 220-221 (1966).

[11] S.K. Tiku, C.K. Lau, and K.M. Lakin, "Chemical Vapor Deposition of $\mathrm{ZnO}$ Epitaxial Films on Sapphire," Appl. Phys. Lett. 36, 318-320 (1980).

[12] M. Matsumoto, I. Kah, and Y. Murayama, Tech. Group Ultrasonics US 78-47, 17 IECE Japan (1979).

[13] T. Yamamoato, T. Shiosaki, and A. Kawabata, "Characterization of $\mathrm{ZnO}$ Piezoelectric Films Prepared by RF Planar- Magnetron Sputtering," J. Appl. Phys. 51, 3113-3120 (1980).

[14] B.T. Khuri-Yakub and J.G. Smits, "Reactive Magnetron Sputtering of ZnO," J. Appl. Phys. 52, 4772-4774 (1981).

[15] G. Heiland and H. Ibach, "Pyroelectricity in Zinc Oxide," Solid State Commun. 4, 353 (1966).

[16] Landolt-Borntein Tables, Volume 15, edited by O. Madelung, H. Schulz, and H. Weiss, Springer-Verlag, Berlin, 1980. 